This item was submitted to Loughborough's Research Repository by the author.

Items in Figshare are protected by copyright, with all rights reserved, unless otherwise indicated.

\title{
Integrating disaster risk management into construction: A UK perspective
}

PLEASE CITE THE PUBLISHED VERSION

http://www.tandf.co.uk/journals/titles/09613218.asp

PUBLISHER

(C) Taylor \& Francis

VERSION

SMUR (Submitted Manuscript Under Review)

LICENCE

CC BY-NC-ND 4.0

REPOSITORY RECORD

Bosher, Lee S., Andrew R.J. Dainty, Patricia M. Carrillo, Jacqueline Glass, and Andrew D.F. Price. 2019. "Integrating Disaster Risk Management into Construction: A UK Perspective". figshare.

https://hdl.handle.net/2134/4243. 
This item was submitted to Loughborough's Institutional Repository (https://dspace.lboro.ac.uk/) by the author and is made available under the following Creative Commons Licence conditions.

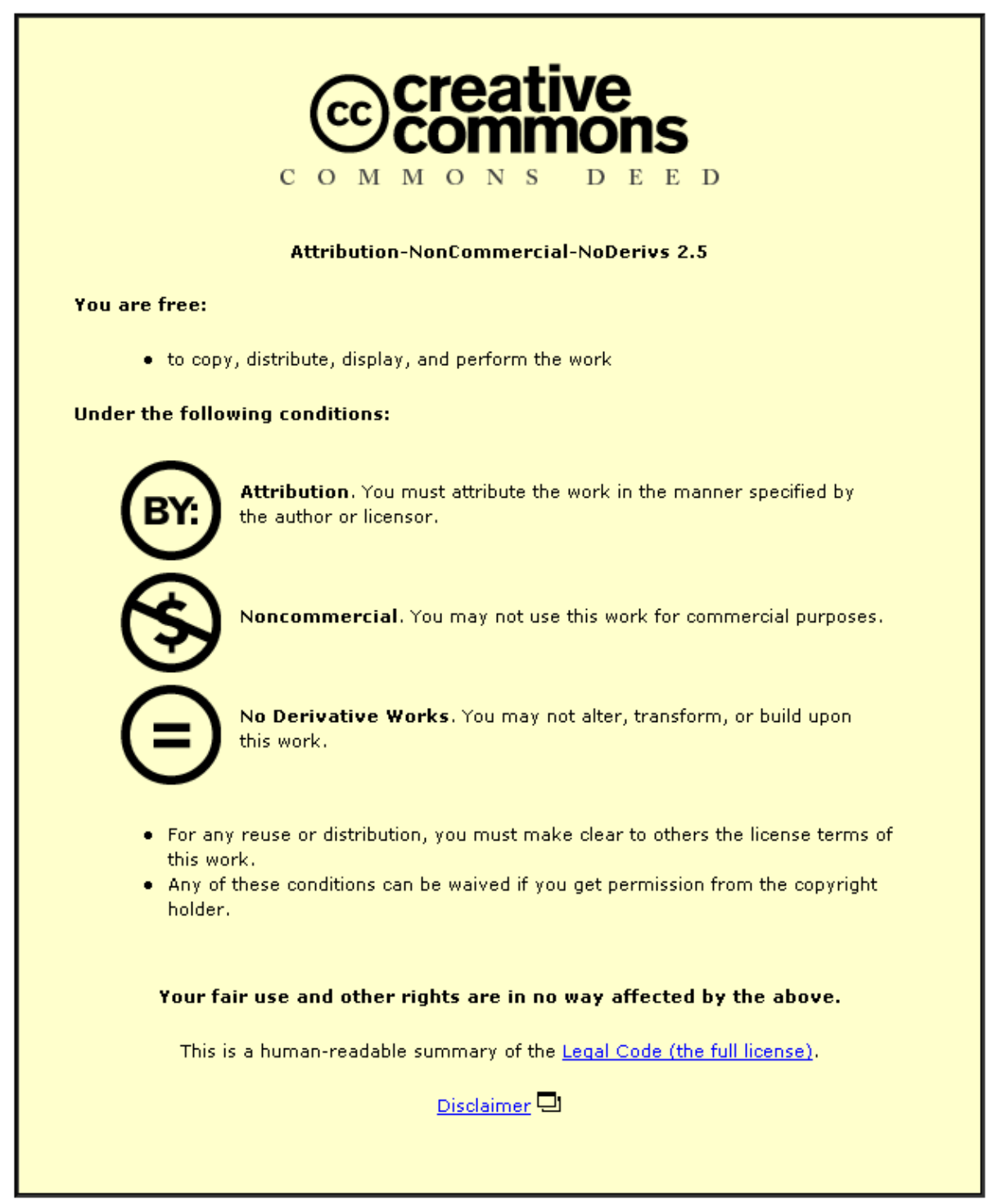

For the full text of this licence, please go to: http://creativecommons.org/licenses/by-nc-nd/2.5/ 


\title{
INTEGRATING DISASTER RISK MANAGEMENT INTO CONSTRUCTION: A UK PERSPECTIVE
}

\author{
Lee Bosher (corresponding author) < L.Bosher@lboro.ac.uk $>$ \\ Andrew Dainty \\ $<$ A.R.J.Dainty@lboro.ac.uk $>$ \\ Patricia Carrillo \\ $<\underline{\text { P.M.Carrillo@lboro.ac.uk }}>$ \\ Jacqueline Glass \\ $<$ J.Glass@lboro.ac.uk $>$ \\ Andrew Price \\ $<\underline{\text { A.D.F.Price@lboro.ac.uk }>}$
}

\section{Address for Correspondence}

Department of Civil and Building Engineering, Loughborough University, Leicestershire, England, LE11 3TU 


\title{
INTEGRATING DISASTER RISK MANAGEMENT INTO \\ CONSTRUCTION: A UK PERSPECTIVE
}

\begin{abstract}
Although most disasters are not entirely unexpected and therefore can, to varying degrees, be mitigated for, the construction sector in the UK does not play a sufficiently integrated role in disaster risk management. This paper reports on research that is developing a knowledge database and decision support framework to enable more effective disaster risk management strategies from a construction perspective. Questionnaire surveys and semi-structured interviews were used to review the opinions of professionals involved with activities such as emergency planning, construction, urban planning and insurance on issues related to disaster risk management in the UK. The findings suggest that knowledge and awareness of integrated approaches is poor and the construction sector as a key stakeholder and potential resource is not being used sufficiently. The key recommendations are: construction related stakeholders need to become more involved in groups such as Local Resilience Teams and Forums; risk and hazard awareness training needs to be integrated systematically into the professional training of architects, planners, engineers, developers etc.; and the construction sector should embrace and pre-empt regulatory changes regarding resilient construction requirements.
\end{abstract}

[Words 7,899 (exc. endnotes); 8,449 (inc. endnotes)]

Keywords: Construction sector, disaster risk management, resilience, UK 


\section{INTRODUCTION}

The construction decision-making process requires an in-depth integrated understanding of how to avoid and mitigate the effects of emergencies and disasters (Hamelin \& Hauke 2005; Bosher et al 2006a). In order to be effective, such resilience needs to be systematically 'built-in' to the planning and design processes and not simply added on as an after thought. However, it is unclear whether this is being achieved in the United Kingdom (UK).

Some advances have been made in recent years to incorporate the roles of construction professionals into debates regarding topics such as climate change and sustainability. However, the integration of construction professions with processes associated with Disaster Risk Management (DRM) has largely been ignored (Spence and Kelman 2004). Thus, although many disasters are not entirely unexpected and can be mitigated for, it is reasonable to hypothesise that at present, the construction sector in the UK does not play a sufficiently integrated role in DRM (Bosher et al 2006a).

Current and potential threats need to be considered during the entire construction decision-making process ${ }^{1}$. Commentators have posited that the impact of global climate change (which is arguably both natural and anthropogenic in nature) has increased the frequency of natural disasters, and will further increase the frequency of natural disasters in the future (Munich Re 2003). The impact of these events can be psychological, sociological and political, but they are typically reported in economic terms. Globally, economic losses due to natural weather 
catastrophes have increased ten-fold in the last 40 years (Munich Re 2003). The Association of British Insurers (ABI) states that in the UK, between 1990 and 2000, weather related insurance claims totalled between $£ 360 \mathrm{~m}$ and $£ 2.1$ bn a year (ABI 2003). In economic terms, both at national and global scales, the damages from flooding are greater than those from any other natural disaster (DTLR 2001).

Amidst growing concern for the safety and security of the UK's built environment in relation to natural and human-induced threats, this paper reports on research which has explored the construction sector's knowledge of, and involvement with, DRM in the $\mathrm{UK}^{2}$. The main objectives of this study were to: examine perceptions of a range of respondents regarding an indicative selection of the most and least significant natural and human-induced threats to the UK's built environment; assess current awareness of a range of construction disciplines regarding DRM processes; and ascertain the potential role of the construction sector in DRM activities. Based on a questionnaire survey and in-depth interviews with a variety of industry stakeholders it proposes ways in which the construction sector can become more involved. This paper reports on an initial survey of a subject that has not yet been sufficiently researched in the UK and for which little evidence is available. The findings presented here should not be seen as conclusive, but rather as a foundation for further research and for the development of practical initiatives to encourage DRM within industry practices. 


\section{BACKGROUND}

Threats to the built environment in the UK are diverse and include extreme natural hazards (such as floods and storms) and human induced hazards (such as terrorism and explosions at industrial sites). Typically, these hazards cause minor disruption to the economy, infrastructure and residents of the UK but some commentators (UKCIP 2002; Keane 2005) believe that the magnitude and frequency of these extreme events are increasing and that disasters in the UK may also increase. For instance, UKCIP (2002) predicts a possible increase in winter peak river flows of up to $20 \%$ by 2050 due to climate change; the ABI suggests that this would approximately double flood risk, with a $0.5 \%$ ( 1 in 200 years) flood zone becoming a 1\% (1 in 100 years) flood zone (ABI 2004).

Recent figures state that some $27 \%$ of new housing is located in flood hazard areas (Crichton 2005b). Flooding is the most frequent and costly threat to homes in the UK (DTLR 2001) and climate change is likely to increase this problem (Crichton 2005a). Therefore, it is important to educate professions in the constructions sector about, amongst other hazards, the risk of flooding to forthcoming and existing developments rather than relying on the planning system.

Windstorms are also considered to be amongst the most damaging of the natural perils covered by property insurers in the UK (ABI 2003). However, there appears to be some contention as to whether it is old or new housing stock that is at most risk. For example, the ABI (2003) and Spence et al. (1998) state that generally the 
older the building the more vulnerable it is to wind damage. However, Crichton (2005a) concluded after a pilot study on the same topic, that modern buildings in England and Wales are much more vulnerable to damage than older ones, mainly because older buildings were "over engineered" while modern ones are built to building standards and codes that are not sufficiently resilient. The London Climate Change Partnership have claimed that in much of England, buildings are not currently designed to withstand the severity of storms experienced in other parts of Europe (LCCP, 2002). Therefore, the threats from events such as flooding and wind-storms (amongst other threats such as droughts and heat waves) are likely to increase due to the pressures of climate change, posing important issues for the construction decision-making process.

The insurance sector in the UK has called for action from public and private stakeholders to be taken in flood risk areas to ensure the insurance sector can continue to provide the service it currently does (Huber 2004). For example, Vivian et al. (2005) have stated that there is a need for the full enforcement of planning guidance by local authorities to guard against unprotected and irresponsible building on floodplains. The role of the insurance sector as a driver for flood risk avoidance in the UK may be critical, especially as there is no government compensation mechanism or insurance scheme for the victims of floods, with $95 \%$ of homes being insured by the private insurance sector (Crichton 2004). 


\section{Disaster Risk Management}

Disaster risk management is defined by the United Nations as:

"The systematic process of using administrative decisions, organization, operational skills and capacities to implement policies, strategies and coping capacities of the society and communities to lessen the impacts of natural hazards and related environmental and technological disasters. This comprises all forms of activities, including structural and non-structural measures to avoid (prevention) or to limit (mitigation and preparedness) adverse effects of hazards.” (UN/ISDR 2004:17)

The United Nations has thus adopted a concept of DRM that combines activities over four phases: Pre-emergency preventive and mitigating actions; Formulation of emergency plans and preparedness activities; Emergency response interventions; and Short-term rehabilitation and longer-term reconstruction. Organisations such as the United Nations, the ProVention Consortium ${ }^{3}$ and the UK Government's Department for International Development (DFID 2006) have highlighted the importance of 'mainstreaming' DRM as part of an initiative to build collaboration between stakeholders in order to reduce the impact of disasters by integrating disaster risk reduction into development policies.

"Flawed development often lies at the heart of disaster risk and therefore risk reduction strategies and measures are most effective when integrated into the framework of overall development. In principle, risk reduction should not be considered as an end in itself which requires incorporation 
into development but rather as an integral component of all development processes in the first place" (ProVention Website 2006)

The Hyogo Framework for Action 2005-2015 (UN/ISDR 2005) urges that disaster risk should be addressed in urban planning, along with other technical matters, such as housing. Amongst other requirements, it calls on governments to mainstream disaster risk considerations into planning procedures for major infrastructure projects. However, little research has been done on how risk reduction can be effectively mainstreamed in the developmental sectors of other types of construction projects and activities such as urban planning and housing (Wamsler 2006).

Schneider (2002) stated that DRM has often been viewed as a reactive profession because activities such as risk reduction and hazard mitigation are rarely seen as urgent. DRM needs to be more holistic and new initiatives found in order to ensure that associated strategies are viewed as a shared responsibility that includes issues such as hazard mitigation (Pelling 2003; Trim 2004) and land-use planning (Burby 1998; Burby et al 2000; Warmsler 2004). The concept of hazard mitigation begins with the realisation that many disasters are not unexpected (Mileti 1999), and the impacts of many natural and human-induced hazards can therefore be reduced. With particular reference to natural hazards, it is common to discuss two types of hazard mitigation, as summarised below. 
1) Structural mitigation - such as the strengthening of buildings and infrastructure exposed to hazards (via building codes, engineering design and construction practices, etc.).

2) Non-structural mitigation - includes directing new development away from known hazard locations through land use plans and regulations, relocating existing developments to safer areas and maintaining protective features of the natural environment (such as sand dunes, forests and vegetated areas that can absorb and reduce hazard impacts). These non-structural mitigation initiatives can have significant value in risk and cost reduction (Godschalk et al 1999). For example, in 1988 the United States the Stafford Act (amended in June 2006) was critical in advocating the proactive rather than reactive approach to disaster management (a shift from a disaster driven system to a policy- and threat-driven system).

The construction sector can play an important role in the structural elements of mitigation, while developers and planners (Wamsler 2006) should be able to positively influence the non-structural elements of mitigation ${ }^{4}$. DRM should therefore be concerned with people's capacity to: manage their natural, social and built environments; and take advantage of it in a manner that safeguards their future and that of forthcoming generations. Part of this shared responsibility could be achieved by integrating construction professionals, that possess the knowledge and experience of how to design, build, retrofit and operate what are typically bespoke built assets, into the DRM framework (Bosher et al 2006a). 


\section{Disaster Risk Management in the UK}

DRM largely falls within the remit of the UK Government's Cabinet Office under the guise of 'civil contingencies' but also includes a range of initiatives by government agencies such as the Department for Environment, Food and Rural Affairs (DEFRA) and the Environment Agency and non-governmental agencies such as the British Red Cross. The Civil Contingencies Act (Cabinet Office 2004) was introduced in 2004 in an attempt to deliver a single framework for civil protection in the United Kingdom to meet the challenges of the $21^{\text {st }}$ century. The Act is separated into two substantive parts: local arrangements for civil protection (Part One); and emergency powers (Part Two). The overall objective for both parts of the Act was to modernise outdated legislation but the principal emphasis of the act is on emergency response and as a result it does not sufficiently achieve the more proactive requirements of DRM.

Part One of the Act covers local arrangements for civil protection and sets out clear expectations and responsibilities for front line responders at the local level to ensure that they are prepared to deal effectively with the full range of emergencies from localised incidents through to catastrophic emergencies. It divides local responders into two categories as presented in Table 1. The Civil Contingencies Act 2004 has therefore put in place a framework that enables a wide range of stakeholders, such as transport operators, utilities companies and communications providers, to be integrally involved with emergency management planning, but not the broader processes encouraged within the DRM framework. In addition, the extent to which construction professionals are involved within this framework is 
unclear (Bosher et al 2006a). This is a particularly pertinent issue because many of the organisations listed in Table 1 are the construction's largest clients that also possess the skills and resources to become integrated stakeholders in DRM.

\section{The UK Construction Sector}

The built environment is generally designed, built, maintained, operated and decommissioned by the construction sector, which can be defined as "all those firms involved directly in the design and construction of buildings" (Morton 2002:39) and includes civil engineering and infrastructure work such as roads, bridges and railways. The UK construction sector is worth some $£ 65$ billion a year, accounts for eight per cent of gross domestic product, and employs 1.9 million people (NAO 2001). The construction sector is a critical component of not only the nation's economy (Hillebrandt, 2000), but is also a fundamental factor in the quality of life and the ability of the government to achieve policy requirements. If a resilient built environment is to be achieved it is feasible that the construction sector in the UK should become integrated into the DRM framework (Bosher et al 2006a).

The construction sector is currently involved with disaster response on an ad-hoc basis (Bosher et al 2006b) and it would make sense if construction professionals were better integrated within DRM, through, for example, structural mitigation activities via consultation related to the design and engineering of structures. However, as Lorch (2005) comments, some of the non-technological problems of 
disaster management are a demonstration of the disciplinary boundaries within the scientific community and between the scientific and policy communities. Consequently, there is a need for policy makers, practitioners and academia to realise that DRM issues should be more integrated into training. For example, the Royal Institution of Chartered Surveyors (RICS) has founded a Presidential Commission on Disaster Management that is pushing for the inclusion of DRM issues as core elements of training. Arguably, similar initiatives need to be established by other professions because in forthcoming years it is possible that clients will include resilience and hazard mitigation awareness as one of their prequalification criteria for contractors and product suppliers.

\section{METHODOLOGY}

Between September and December 2005, a range of professionals involved with construction, insurance, emergency management, local and national government, urban planning, and academic research completed 102 questionnaire surveys; the data from the surveys was analysed using $\mathrm{SPSS}^{5}$. The response rate to the questionnaire survey was low at 28\% (of 367 questionnaires that were sent, 102 were completed). It was useful to assess which professions were most engaged with the topics covered by the questionnaire by measuring the questionnaire response rate for each sector. Above average responses to questionnaires were provided by: engineering consultancies (54\%); the insurance/risk sector (46\%); academia/research (36\%); and Government Agencies (33\%). Below average responses were from: local authority urban planners (13\%); small to medium sized construction companies (SMEs) ${ }^{6}(15 \%)$; and 'property developers" ${ }^{7}(22 \%)$. 
Follow up telephone calls and e-mail correspondences to a broad range of the non-responders highlighted that the main reason for not returning a questionnaire was due to the individual perceiving that the topics covered by the questionnaire (such as awareness of and involvement with DRM processes, hazard identification and mitigation, and integrated training) were not applicable to them.

The questionnaire survey findings were augmented via the use of semi-structured, in-depth interviews conducted between January and March 2006, with 17 respondents from a range of disciplines. These interviews covered the topics raised in the questionnaire surveys and gave the respondents opportunities to elaborate and provide examples of good and best practice as well as suggestions as to which professions should be more or less involved in DRM issues. Over 20 hours of interview transcriptions were analysed using NUD*IST qualitative data analysis software.

\section{RESULTS}

As discussed earlier, threats to the UK built environment are diverse and include extreme natural and human-induced hazards. However, some commentators (such as UKCIP 2002; Keane 2005) believe that the magnitude and frequency of extreme events are increasing. As such, current and potential future threats need to be considered during all stages of the construction decision-making process. In view of this, the project sought the views of the respondents regarding perceptions of what they considered to be the most or least significant threats to the built environment from a UK specific list of indicative hazards ${ }^{8}$ (Figure 1). 
Figure 1 shows that the most significant threats to the built environment in the UK were considered to be floods, climate change, ageing/inadequate infrastructure, and inadequate urban planning. Minor threats were perceived to be civil unrest/war and terrorism. Respondents with primary responsibility for public safety, such as urban planners and emergency managers, were the only disciplines that perceived terrorism to be a significant threat to the UK's built environment.

"It is important that we do not rush to retrofit buildings that may be at risk of terrorist attack, whilst at the same time neglecting to consider the more real, but possibly less 'headline grabbing', threats from increased storms, flooding and ageing infrastructure.” (Interview 2 with Civil Engineer)

\section{Perception of threats by sector}

All sector categories perceived the threat from flooding to be a significant threat to the built environment, as shown in Table 2. The respondents involved with the construction sector considered 'wind storms', 'coastal erosion' and 'terrorism' to be of no threat to the built environment, which is in contrast to the responses from urban planners. The respondents from the insurance sector substantiated the findings of research by the ABI (2003), which concluded that windstorms were considered to be amongst the most damaging of the natural perils covered by property insurers in the UK. 
Respondents from the utilities sector and developers did not view climate change as a significant threat, while trade representation, urban planners and engineering consultants considered climate change to pose a significant threat. Further indepth analysis of the data did not produce any statistically significant observations or correlations relating to differing perceptions, but this may be symptomatic of low sample size. Nonetheless, differing opinions occur and to some degree these opinions are delineated across disciplinary lines. It is difficult to assess the reasons behind these differing perceptions but they may be significantly influenced by the types of training (formal and informal/pre-qualification and 'onthe job') that the professions receive; this is an issue that is worthy of a further indepth study.

It is thus important to recognise that essential differences, such as perceptions of threats and risk, exist between professional people from different backgrounds (Pavlica and Thorpe 1998). Indeed, differences exist between the disparate professionals working in the area of disaster management (Trim 2004) and construction (Morton 2002) because an individual's identity is: formed by history, tradition, politics and education; influenced by management learning and development; and shaped by factors associated with organisational change (Pavlica and Thorpe 1998), and types and methods of employment (Morton 2002). These differences need to be considered when attempting to integrate a wide range of professions into any strategic framework, but before this can be done it is essential to gain an insight as to who is (and who should be) involved with DRM. 


\section{Awareness of who is currently involved with DRM}

An integral part of this study involved the identification of which sectors are currently involved with DRM in the UK. Approximately one in six of the respondents were not aware of whether the construction sector is involved with DRM related activities. Nearly half of the respondents stated that the construction sector is involved on an ad-hoc basis (but mainly related to emergency response, search and rescue, and reconstruction). Three quarters of the respondents agreed that there is a pressing need for professions associated with the construction sector to become more involved with disaster risk management in the UK (only $3 \%$ disagreed). Of those who construct the built environment (in contrast to those who plan and govern the built environment) only $30 \%$ are involved in most cases and one third are involved on an ad-hoc basis.

The majority of respondents $(81 \%)$ stated that local authorities are involved with DRM but that their involvement is largely related to emergency response activities. This may highlight a potential weakness regarding the role of local authority planners, because as Wamsler (2006) suggests, planners are not sufficiently involved with non-structural mitigation. Also, the majority of the respondents $(75 \%)$ did not feel that developers or clients were involved with DRM. In contrast $57 \%$ of developers and $71 \%$ of engineering consultants felt that developers and clients were involved. Two thirds of the respondents believed that civil engineers are involved with DRM but $69 \%$ of emergency managers and $67 \%$ 
of professionals in the insurance and risk sectors believe that civil engineers are not involved. Again, awareness of who is responsible for DRM activities appears to be very mixed and in some cases extremely limited.

\section{Future involvement with DRM}

Over half of the respondents stated that urban planners, designers, engineers (civil and structural), developers, clients and architects should be more involved with DRM than they are currently (refer to Table 3). Interestingly, however, the two respondents from local authority urban planning departments did not agree that they should be more involved. These findings add force to the work undertaken by Wamsler (2004), which identified a lack of integration between the working fields of risk reduction and urban planning and illustrated how urban planning and the occurrence of disasters interact.

The two respondents from utilities companies did not think they were sufficiently involved with DRM; in stark contrast, the respondents that were not from this sector stated that utilities companies were significantly involved with DRM. It is possible that this may reflect a delay between what has been set out in legislation, such as the Civil Contingencies Act, regarding the involvement of utilities companies and the establishment of the working groups and sub-groups that constitute the framework. Whatever the reasons may be, there is presently little evidence that the respondents are sufficiently informed of who is and who is not involved with DRM in the UK; this is an issue that should be resolved urgently. 
There is a need for policy makers, practitioners and the academic community to realise that DRM needs to be better integrated than in the past. For example, hazard mitigation and urban planning should not be a niche issue in the construction sector and knowledge about disruptive events needs to be incorporated into the mainstream risk-management process (Lorch 2005). In view of this, the extent to which the respondents believed that hazards and risk reduction issues had been integrated into their professional training was assessed and the results have been presented in Table 4.

The findings suggest that awareness of natural/human-induced/climate change related hazards tends to be most prominent with respondents who govern/advise on the built environment (such as those representing the Environment Agency, DEFRA and the insurance sector), rather than those who actually design, build, maintain and operate the built environment. The respondents from the construction sector (including developers and trade representation) stated that the issues highlighted in Table 4 were not typically integrated into their professional training. Therefore, the findings from the questionnaires and interviews suggest that the levels of training provided to construction professionals on the awareness of these hazards is insufficient and needs to be more integrated within their professional training than it has been in the past. 


\section{Roles within Regional/Local Resilience Forums}

Government Offices in the UK, through the work of the Regional Resilience Forums (RRFs) and Local Resilience Forums (LRFs), have an important role to play in the promotion and implementation of the regional tier of "emergency management' as set out in the Civil Contingencies Act 2004 (Cabinet Office 2004). These RRFs and LRFs could also have an important role to play by enabling the integration of urban planners, developers and the myriad construction disciplines into DRM.

Flood Liaison and Advice Groups (FLAGS) also provide a network through which stakeholders have an opportunity to influence local policies, and advise local planners and have been fundamental to the Scottish strategy of flood risk reduction (Crichton 2005c). However, FLAGS are specific to Scotland, although there are no legal impediments to prevent councils in England and Wales from establishing participation groups along the same lines (Crichton 2005c). Therefore, RRFs and LRFs are not the only forums where DRM could be mainstreamed into the construction decision-making process ${ }^{9}$. Nonetheless, because the vast majority (93\%) of the respondents in this study were based in England and Wales, it was deemed most appropriate to enquire about their involvement with RRFs and LRFs.

RRFs and LRFs have been formed to bring together key players within each region of England and Wales, such as local authorities, central government 
agencies, the armed forces and the emergency services. This study has assessed the extent to which the respondents are involved with these RRFs/LRFs. Table 5 shows that emergency managers (as one would expect) are likely to be regularly involved with RRF/LRFs. However, professions associated with the construction sector and development are not currently involved with RRF/LRFs.

These findings suggest that despite the introduction of the Civil Contingencies Act 2004, there is still a lack of involvement from private sector stakeholders (91\% of respondents not involved) compared to public sector stakeholders $(62 \%$ of respondents involved) ${ }^{10}$. Arguably, the DRM sector needs to initiate greater involvement from private sector stakeholders by, for instance, encouraging representatives from construction companies or contractors to become involved with RRFs and LRFs. For example, those involved with construction projects could be classed as temporary (whilst they are involved with a project under a certain local authority's jurisdiction) 'Category Two responders' (as a requirement of the Civil Contingencies Act 2004).

"Construction Sector professionals need to be more involved with the decision-making process, such as via Resilience Forums, but time needs to be made for this to occur. I think that making us temporary Category Two responders would be a good idea, if the time, training and resources were made available. For example, engineers need to be more involved with local authority decision making; there needs to be a mix of private and public sector inputs.” (Interview 2 with Civil Engineer) 
This would mean that representatives for the various construction stakeholders would be obliged to become intrinsically involved with RRFs and LRFs. This could be made a prerequisite for any contractor/organisation that is involved with the construction decision-making process, especially for any large-scale projects (such as hospitals, transport infrastructure, or any other project that is essential to the safe and secure operation of the built environment).

“The construction sector should be more involved with Resilience Forums, particularly with large-scale projects. As many stakeholders as possible should be involved at the conceptual stage, sharing best practice is key, but the mechanisms need to be in place such as a formal national framework that trickles information down. There is a desperate need for people to talk to each other about these issues.” (Interview 3 with Insurance Consultant)

To make this suggestion more workable it may be necessary for the relevant parties to provide a representative that holds a suitably broad perspective of the project being undertaken. This representative should ideally possess sufficient knowledge of the potential hazards that could affect the project and be aware of the impacts of the project regarding safety, security and sustainability matters.

"I am not sure if involvement with Regional Resilience Forums would be practical having communicated with people on the sites. But making involvement a local requirement through these forums would be a good move. However, it would be a lot to ask, more training would be required. The business element is a key driver or constraint - depending on the awareness of the organisation. It wouldn't necessarily have to be an 
engineer that gets involved with the resilience forums, but someone who could hold a strategic interdisciplinary viewpoint.”

(Interview 4 with Engineering Consultant)

\section{Improved training}

Because the impacts of natural and human-induced hazards have not been sufficiently integrated into the professional training of people in the construction sector, as highlighted in Table 4, improvements to training programmes would be required.

"Many professions involved with the construction sector are too disjointed; they tend to work in isolation. Current training needs to evolve to become more integrated and appreciate issues such as natural and manmade hazards.”

(Interview 12 with Quality Manager - Construction)

At the same time research communities need to be more integrated if the temporal concepts of life cycle, hazard and impact are to be better understood in the future. Lorch (2005) believes that higher education and training can play a major part in the integration of hazard, vulnerability and risk reduction principles into the domain of built environment students and asks: "Should we be investigating the capabilities of the built environment under extreme circumstances as well as subtle, protracted circumstances?” (Lorch 2005:210). For example, in Europe, much work has been done to re-educate architects to design eco-friendly and more 
resilient buildings, which not only have lower carbon emissions, but are more resistant to floods and storms (Roaf et al. 2005).

"The construction sector possesses a lack of awareness of these issues, disaster risk management needs to become a core skill in the training of construction professions, and then hopefully this will lead to a more appropriately planned, designed and constructed built environment, but this will need a holistic approach. The construction industry likes to throw buildings up without thinking of the consequences. What mistakes are we making now that will make future generations think, what on earth were they thinking, why was that allowed?"

(Interview 9 with Engineering Consultant)

The new procurement paradigms embodied within performance based contracting may also be relevant in encouraging the need for broader and longer term perspectives with regards to hazard mitigation in the built environment design and construction process. The contractual and professional imperative to consider hazard resilience and mitigation will almost certainly place new requirements on educators to integrate such thinking into their curricula in the future.

\section{Increasing competitiveness}

The construction sector should embrace, and possibly pre-empt, regulatory changes regarding resilient construction requirements and use it as an opportunity for competition within the sector, nationally and globally and as a litigation avoidance measure (Bosher et al 2006a). In this way the construction sector could 
significantly contribute towards actions related to mitigation initiatives whilst viewing the required innovations as opportunities to become leaders in the field of resilient structures. The following quotes highlight the range of views from the interviewees on this topic.

"I can see the value of bringing hazard/risk assessors on board in a consultancy role. How much will this cost though? Five or ten years ago the situation was a lot different than it is now. If I had gone to clients with suggestions for passive this, sustainable that and green roofs, I would have been laughed out of the room, but now these issues are central (or becoming more central) to the design, planning and construction of projects. I can see that the issues we are talking about now regarding resilient design and hazard mitigation features will also become central issues, sooner rather than later. I just hope you don't have to get laughed out of too many rooms before the mindset changes." (Interview 13 with Engineering Consultant)

"The issue we need to consider is that sustainability and resilience is a bit of a misnomer. The economy is largely built on the construction sector but the turnaround of buildings is about 30 years, so why design buildings to last for longer than 50 years, what is the point if they are going to be demolished in 20-30 years time? Technically speaking, everything built 3040 years ago is now below the required standards!"

(Interview 8 with Civil Engineer) 
"We are starting to look at mitigation strategies more and more, but if we are doing this, it isn't due to altruism, it is motivated by concerns about litigation.” (Interview 11 with Senior Manager - Construction)

Consequently, although some of the respondents are appreciative of the potential benefits of DRM, there also appears to be a degree of scepticism from the construction sector about involvement with some elements of DRM such as hazard mitigation and resilient design.

\section{LACK OF KEY INPUT FROM SOME SECTORS}

During this research, most of respondents highlighted that there were two specific sectors that were significantly under involved with DRM related issues; namely urban planners and developers. Furthermore, developers (22\%) and urban planners $(13 \%)$ were amongst those that provided below average returns to the questionnaire survey. As highlighted earlier in this paper, this may indicate a lack of engagement with the topics covered in the questionnaire, such as DRM and hazard mitigation. This is a particularly important observation because over $50 \%$ of the respondents stated that inadequate urban planning was a significant threat to the built environment in the UK and that urban planners have the potential to play a key role in the mitigation of hazards. A number of comments made by the respondents during the interviews supported these points. 


\section{Urban Planners ${ }^{11}$}

All four local authority emergency management interviewees stated that despite their own efforts, they had not been able to convince urban planners (within their own local authorities and typically located in the same building) the value of working together on the issues highlighted in this paper.

"We should get urban planners more involved. I do not work with urban planners, although I tried to, but they are not aware of the issues. However, I think things are starting to change slowly. The planning of our communities needs to be more multi-disciplinary, more integrated."

(Interview 10 with Senior Emergency Planner)

"Urban planners need to be better aware of the issues and then have the powers to stop inappropriate developments occurring."

(Interview 16 with Engineer - Defra)

"Urban planners need to be more involved in the debate, this is a key issue, are they aware of the issues? It doesn't appear to be the case when housing estates and critical infrastructure have been allowed to be built on flood plains. What are their terms of reference, are they just following strict procedures? Town planners ideally need to be more than planners, they should be aware of all the issues."

(Interview 9 with Engineering Consultant) 
These are just some of the comments that were made regarding the lack of awareness and involvement of urban planners in DRM in the UK. In contrast, the one urban planner that was willing to be interviewed, stated;

"Unfortunately there is nothing that town planners can do to stop people from reusing their buildings. We can stop them from building an extension but we can't stop them from moving back into a property located in a flood risk area. We have to deal with the legacy of historical developments, how ever inappropriate they are. This is perhaps where the insurance sector needs to play a more active role by not providing insurance to people in high risk properties.”

(Interview 14 with Urban Planner)

This discussion reinforces the results of research conducted by Wamsler (2004), which identified a lack of integration between the working fields of risk reduction and urban planning and illustrated how urban planning and the occurrence of disasters interact. Wamsler (2006) also suggested that urban planners often do not perceive non-structural activities, as well as small-scale risk reduction measures, as part of their work, thus impeding the development of mutual understanding with other professions. 


\section{Developers}

"The construction sector needs to be made more accountable for what they build and design. Particularly developers, they need to take more responsibility for their actions; they only appear to be interested in making profits and covering their backs legally. You would like to think that if developers incorporate Sustainable Drainage Systems (SUDS), eco-friendly materials, and energy efficiency into their developments then they could charge a bit more for those properties. Their practices appear to be rather unethical in resilience and sustainability terms, while at the same time the planners don't appear to have enough clout to enforce the guidelines, or the guidelines need to be stricter.”

(Interview 15 with Hydrologist - Scottish Environment Protection Agency)

"Residential developers may be a constraint, I have yet to meet a residential developer that is proactive to take up these issues, because they are motivated by profits and the legal aspects (reducing the chance that they can be sued by the general public), possibly at the cost of resilience and sustainability. Resilience is left as the responsibility of the person who will be likely to live or work in the building."

(Interview 4 with Engineering Consultant) 
These are two examples of the comments that were made regarding the perceived inappropriate motivation of property developers. In contrast the one representative of a property developer that was available to be interviewed, stated;

"It is key that our products (houses) are durable and meet the requirements of the customer (such as layout, heat conservation, water conservation etc.). We as the developer, quite coldly, need to make a profit on the development we are involved in, whilst taking into consideration the guidelines and regulations, the cost parameters and the location that we have to work in. It is a balancing act and we need to operate within this framework."

\section{(Interview 5 with Chairman of a Property Developer)}

Fundamentally, the main incentive for local government to plan effectively is based on their need for central government resources with the consequence that plans have to be submitted to and approved by central government annually. This forms a dependency relationship where 'bottom-up' priorities are intended to match 'top down' policies (Gillingwater and Ison 2003:554-5). Pragmatically, the planning system intends to allocate appropriate land for appropriate purposes whilst taking account of the use of adjoining land, threats to that land and the needs of the local population. Realistically, the role of the planning system is an impossible one, resolving contradictions and deep rooted conflicts between, on the one hand, competing private interests over the use and development of land and, on the other, public and community interests over property rights and development priorities (Gillingwater and Ison 2003:561). 
The competing interests highlighted here are demonstrated by the current situation with planning guidance and the need for more land in the England and Wales to build more homes. Plank (2005) states that nearly four million new homes are needed over the next 15 years. Current Government policy 'Planning Policy Guidance 3' (ODPM 2000) aims to re-develop 'brownfield' sites first, before looking at 'greenfield' options. According to Planning Policy Guidance 25 [PPG25] (DTLR 2001), previously developed areas in high flood risk locations should be given preference over undeveloped or sparsely developed areas, which are generally not suitable for new development in the floodplain. The Barker report (2004) further speculates on the limitations of an approach that prefers developing 'brownfield' sites over 'greenfield' sites, and whether broader sustainability criteria should be applied to land use decisions. The Association of British Insurers believes that the principle aim of PPG25 (and the under review Planning Policy Statement 25) should be to ensure that new development does not cause any net increase in flood risk for the area (ABI 2004). Some of the England and Wales focused issues highlighted here could be resolved if some lessons were learnt from a range of non-structural mitigation examples undertaken in Scotland (for details refer to Crichton 2005c). Planning ${ }^{12}$ should be a key element in the endeavours of the government and the construction sector to secure the future of the UK's built environment because planning underpins the decisions related to what we build and where we build; planning should be an integral element of DRM. 


\section{THE REGULATORY FRAMEWORK}

Despite the issues raised above, the most common suggestions regarding what needs to be done to strengthen the role of the construction sector within emergency management activities are associated with the need for changes to legislation and guidance.

"I believe that involvement needs to be regulatory driven; we need to make people consider these issues, such as tick off these issues at each RIBA process stage to make sure that people are compliant. It will add to the complexity of the building process but it is a very complex process at the moment anyway. This issue needs to be incorporated into the early design stages. At the moment without the required regulations, if someone sticks their head over the parapet and offers this consultancy service it will be a risk but it could be very useful to be a leader in the game. At the moment organisations can offer bits and pieces of such a service but no one I am aware of can offer the full holistic package."

(Interview 13 with Engineering Consultant)

"We have legislation but I don't think that there is a legislative framework! Regulatory changes are required to produce a level playing field. The government need to get their act together and look at the bigger picture and realise that we need to catch up with other nations but also with the legacy of our ageing infrastructure. The slowly ticking bomb is ageing infrastructure, these are the roads, drainage and sewerage systems that the 
construction sector end up having to patch up and tag new developments onto, this will only get worse as we build more and more homes. We are now at a low point and it is a steep uphill route before we can get things right."

(Interview 11 with Senior Manager-Construction)

"I fear the drivers for change will still need to come from legislation because there is a general lack of initiative from all involved and particularly from those who should be involved."

(Interview 7 with Senior Emergency Management Expert)

Regulatory initiatives are a key component of both structural and non-structural mitigation strategies and amendments to current regulations and guidance will inevitably be required to drive many of the resilience strategies highlighted in this paper. However, Ozerdem (1999) and Lewis (2003) have highlighted that while in most countries legislation does exist in the form of building regulations, codes, standards and guidelines, the regulatory framework is insufficient without regular, strategic, informed and reliable inspection to ensure its enforcement.

Nonetheless, the findings highlighted in this paper also suggest that there are other non-regulatory initiatives that can be taken; initiatives that are driven by awareness of the issues related to a changing climate, integrated multi-hazard awareness training and an appreciation of the importance in protecting and 
retrofitting an ageing infrastructure. For example, Scotland's awareness of the importance of planning as an adaptation tool does not seem to have been recognised to the same extent in England or Wales (Crichton 2005c). By pursuing the non-regulatory initiatives it is likely that the construction sector will be better equipped to anticipate potential regulatory changes regarding resilient design and hazard mitigation.

\section{CONCLUSIONS}

Resilience should be systematically built-in to the planning and design processes not simply added on as an after thought. However, it is clear that this is not currently being achieved. There is a general lack of awareness demonstrated by the respondents regarding who is responsible for, and involved with, DRM initiatives in the UK. Consequently, there is a pressing need for disciplines associated with the construction sector to become more involved with DRM initiatives in the UK. This will be required to pre-empt any likely regulatory changes regarding resilient design and hazard mitigation and the concurrent impact of these changes on clients needs. Any such involvement must also recognise the need for greater integration of inputs into the planning, design and construction/commissioning processes. Awareness of natural/humaninduced/climate change related hazards tends to be most prominent with respondents who govern/advise on the built environment, rather than those who actually design, build and operate it. Therefore, transcending traditional interfaces will be key to hazard mitigation. 
Presently, professions associated with the construction sector and development are not sufficiently involved with important stakeholder groups such as RRFs/LRFs. This is a concern because it is likely that these stakeholder groups that will be integral to the mainstreaming of DRM.

\section{Recommendations}

If a resilient built environment in the UK is to be achieved, DRM needs to become mainstreamed into the construction decision-making process. This could be achieved as follows.

- Involving construction related stakeholders in forums, such as Regional and/or Local Resilience Teams Forums, thereby facilitating the integration of skills that construction disciplines can offer. DRM and construction professions could then become more involved with locational planning and building design codes related to future developments in hazard risk areas; this is of particular importance regarding the protection of critical infrastructures.

- The construction sector should embrace and pre-empt regulatory changes regarding resilient construction requirements and use it as an opportunity for competition within the sector nationally and as a litigation avoidance measure. In this way the construction sector can significantly contribute towards DRM initiatives whilst viewing the required innovations as opportunities to become leaders in the field of resilient construction. The poor survey response from construction SMEs, which constitute the majority of construction sector employees, suggests that there is a pressing need to engage with SMEs if 
DRM is to become more integrated into the construction decision making process.

- Consideration should be given to encouraging the use of performance based contracting, whereby procurement decisions are based around the intended purpose of the product or service. Under such procurement approaches the focus is on making designers and contractors think about the long-term implications and performance of the buildings and structures that they design and construct. Such consideration will inevitably foster more joined up working amongst the professionals involved in the construction processes, changes which must be propagated through the education and training of those involved (see below).

- All stakeholders should increase their awareness of DRM initiatives. Risk and hazard awareness/reduction needs to be systematically integrated into the professional training of architects, planners, civil and structural engineers, developers and construction contractors. Trans-disciplinary training for construction professionals and emergency managers should be encouraged. At the same time clients and consumers should be made aware of the benefits of resilient and sustainable built assets in contrast to the 'lowest price' options.

Ultimately, many of these recommendations may need to be driven by legislative change. It is unlikely that this paper will have sufficient impact to persuade the UK government to make the legislative amendments required to drive these changes. However, if this work can convince just a few of the readers, irrespective of professional background, to advocate and pursue some of the 
initiatives that have been outlined, then the construction sector will be on the right path to integrating DRM into the construction decision-making process and attaining a more resilient built environment.

\section{References}

ABI, (2004), Review of Planning Policy Guidance Note 25: Development and Flood Risk, Consultation Response, October 2004, Association of British Insurers, London

ABI, (2003), The Vulnerability of UK Property to Windstorm Damage, July 2003, Association of British Insurers, London

Bosher L.S., Carrillo P.M., Dainty A.R.J., Glass J., and Price A.D.F., (2006a), Realising a resilient and sustainable built environment: Towards a strategic agenda for the United Kingdom, In Press, Disasters: The Journal of Disaster Studies, Policy \& Management

Bosher L.S., Dainty A.R.J., Carrillo P.M., Glass J., and Price A.D.F., (2006b), The Construction Industry and Emergency Management: Towards an integrated strategic framework, Proceedings of the Information and Research for Reconstruction (i-Rec) Third International Conference on 'Post-disaster reconstruction: Meeting stakeholder interests', 17th-19th May, University of Florence, Italy 2006

Burby R., (ed.) (1998), Policies for sustainable land use, Cooperating with Nature, Joseph Henry Press, Washington DC

Burby, R., Deyle, R.E., Godschalk, D.R. \& Olshansky, R.B. (2000), Creating hazards resilient communities through land-use planning, Natural Hazards Review, Vol. 1 No. 2, pp. 99-106

Cabinet Office, (2004), The Civil Contingencies Act 2004 (Contingency Planning) Regulations, Civil Contingencies Secretariat, Cabinet Office, London

Crichton, D., (2005a), Insurance and Climate Change, Paper presented at Conference on Climate Change, Extreme Events and Coastal Cities, Houston \& London, $9^{\text {th }}$ February, Houston, Texas

Crichton, D., (2005b), Toward an integrated approach to managing flood damage, Building Research and Information, Vol. 33; No. 3; pp.293-299 
Crichton, D., (2005c), Flood Risk \& Insurance in England and Wales: Are there lessons to be learned from Scotland?, Technical Paper 1, Benfield Hazard Research Centre

Crichton, D., (2004), Temporary local flood protection in the United Kingdom An independent assessment, Technical Report, Benfield Hazard Research Centre, University College London

DFID, (2006), Reducing the Risk of Disasters, Department for International Development, East Kilbride

DTLR, (2001), Planning Policy Guidance 25: Development and Flood Risk, December 2001, Department for Transport, Local Government and the Regions, HMSO, London

Gillingwater D., \& Ison S., (2003), Planning for sustainable environmental futures, in Hensher D.A., \& Button K.J. (eds.), (2003), Handbook of Transport and the Environment, Elsevier, Oxford

Godschalk, D.R., Beatley T., Berke P., Brower D.S. \& Kaiser E.J., (1999), Natural Hazard Mitigation: Recasting Disaster Policy and Planning, Island Press, Washington DC

Hamelin J-P., and Hauke B., (2005), Focus areas: Quality of Life - Towards a Sustainable Built Environment, European Construction Technology Platform, Paris

Hillebrandt, P.M., (2000), Economic Theory and the Construction Industry, Third Edition. Macmillan, Basingstoke

Huber, M., (2004), Reforming the UK Flood Insurance Regime: The breakdown of a Gentlemen's Agreement, Discussion Paper 18, ESRC Centre for analysis of Risk and Regulation, The London School of Economics, London

Keane B., (2005), Major Incident and disaster management, The Structural Engineer, 7th June, 83 (11). pp. 22-25

LCCP, (2002), London's Warming: The Impacts of Climate Change on London, London Climate Change Partnership, London

Lewis, J., (2003), Housing construction in earthquake-prone places: Perspectives, priortities and projections for development, Australian Journal of Emergency Management, 18(2), pp. 35-45

Lorch, R., (2005), What lessons must be learned from the tsunami? Building Research and Information, 33 (3). pp. 209-211 
Mileti, D.M. (1999), Disasters by Design: A Reassessment of Natural Hazards in the United States, Joseph Henry Press, Washington DC

Morton, R, (2002), Construction UK: Introduction to the Industry, Blackwell Publishing, Oxford

Munich Re (2003), Topics: Annual Review: Natural Catastrophes, Munich Re Group, Munich

NAO, (2001), Modernising Construction, National Audit Office, London

ODPM, (2000), Planning Policy Guidance 3: Housing, March 2000, Office of the Deputy Prime Minister, London

Ozerdem, A (1999) Tiles, taps and earthquake-proofing: lessons for disaster management in Turkey, Environment and Urbanisation, 11(2), pp. 177-179

Pavlica, K. and Thorpe, R. (1998), Managers' perceptions of their identity: a comparative study between the Czech Republic and Britain, British Journal of Management, 9 (2) pp. 133-49

Pelling, M. (2003) The vulnerability of cities: natural disaster and social resilience, Earthscan, London

Plank, R., (2005), Sustainable Building Construction for Structural Engineers, The Structural Engineer, Vol.83, No.11, 7th June, pp. 30-33

ProVention Consortium, (2006), Website http://www.proventionconsortium.org/ (accessed 10 $0^{\text {th }}$ July 2006)

Roaf, S. Crichton, D., and Nicol, F. (2005) Adapting Buildings and Cities for Climate Change, Architectural Press and Elsevier Press, London

Schneider R.O., (2002), Hazard Mitigation and Sustainable Community Development, Disaster Prevention and Management, 11 (2). pp. 141-7

Scottish Office, (1995), National Planning Policy Guidelines; 7 - Flood, Scottish Office, Edinburgh

Small Business Service Analytical Unit, (2005), SME Statistics UK 2004: Excel Tables, Published at www.sbs.gov.uk/smes (accessed 1st July 2006)

Spence R., and Kelman I., (2004), Editorial: Managing the risks from natural hazards, Building Research \& Information, 32 (5). pp. 364-367

Spence, R. J. S., Fawcett, W. H., \& Brown, A. J., (1998), The windstorm vulnerability of the UK building stock, in Proceedings of the 4th UK Conference on Wind Engineering, Bristol 
Trim, P., (2004), An Integrated Approach to Disaster Management and Planning, Disaster Prevention and Management, 13 (3). pp. 218-225

UKCIP, (2002), Climate change scenarios for the United Kingdom, UK Climate Impacts Programme, April 2002, Swindon

UN/ISDR, (2005), Hyogo Framework for Action 2005-2015: Building the Resilience of Nations and Communities to Disasters, United Nations International Strategy for Disaster Reduction, Geneva

UN/ISDR, (2004), Living with Risk: A global review of disaster reduction initiatives, United Nations International Strategy for Disaster Reduction, Geneva

Vivian S., Williams N., \& Rogers W., (2005), Climate Change Risks to Building: An Introduction, CIRIA, London

Wamsler, C. (2006) Mainstreaming risk reduction in urban planning and housing: a challenge for international aid organisations Disasters, 2006, 30(2) pp. 151-177

Wamsler, C. (2004) Managing Urban Risk: Perceptions of Housing and Planning as a Tool for Reducing Disaster Risk. Global Built Environmental Review (GBER). 4(2). pp. 11-28 


\section{Endnotes}

\footnotetext{
${ }^{1}$ For the scope of this paper the 'construction decision-making process' includes the following interconnected stages: planning, design, construction, operation, maintenance and decommission. 2 The systems and institutions that constitute the nations of the United Kingdom (England, Scotland, Wales and Northern Ireland) are significantly and increasingly different, especially with regard to local authority matters such as land use planning and building standards. Because a significantly large proportion of the respondents were based in England and Wales the majority of recommendations made in this paper are specifically relevant to England and Wales. Where key anomalies occur between different nations within the UK these are highlighted.

${ }^{3}$ The ProVention Consortium is a global partnership of governments, international organisations, academic institutions, the private sector and civil society dedicated to increasing the safety of vulnerable communities and to reducing the impacts of disasters in developing countries.

${ }^{4} \mathrm{~A}$ wide range of disciplines can make positive contributions to non-structural mitigation, such as ecologists, environmental scientists, educationalists and social scientists but this paper will focus on those disciplines more directly associated with the construction decision-making process.

${ }^{5}$ The 'Statistical Package for the Social Sciences' (SPSS) is a computer software program for statistical analysis in social science research.

${ }^{6}$ According to the Small Business Service Analytical Unit (2005) in 2004 83\% of construction sector employees in the UK work for SMEs (<249 employees) with employees in Small Enterprises ( $<49$ employees) constituting $41 \%$ of the construction sector. This suggests that, in view of the poor survey response from SMEs, there is a pressing need to engage with SMEs if disaster risk management is to become more integrated into the construction decision making process.

7 'Property developers' (hereafter referred to as 'developers') have been defined in this study as 'small to large scale commercial entities predominately involved in the business of realising a financial gain from land that they have developed for residential or commercial purposes'.

${ }^{8}$ The indicative list of hazards in the UK that was provided to the respondents did not include hazards such as earthquakes, volcanoes, tsunamis and meteorites as these (in the present climate) were not considered by the authors to be pertinent to the UK. In addition fire hazards were omitted from the survey because such hazards are already encompassed by existing building and design regulations.

9 Other forums that could be utilised include Flood Action Groups in England and Wales, Flood Liaison Action Groups in Scotland and the British Red Cross for example.

${ }^{10}$ These figures indicate a significant relationship between private and public sector stakeholders and involvement with RRFs/LRFs (with a 99\% confidence level): $\chi^{2}=41.517$; significant, $\mathrm{p}<0.01$. ${ }^{11}$ When comparing the different approaches to planning between Scotland and England, one important measure stands out, namely the existence in Scotland of Flood Liaison and Advice Groups. Most Scottish local authorities, including all with a potentially serious flood hazard, have set up FLAGS in line with the recommendations of the relevant planning guideline (Scottish Office 1995), and these now cover more than $90 \%$ of the population (Crichton 2005c).

${ }^{12}$ Because it appears that a significant level of concern has been articulated by the respondents regarding the insufficient roles of urban planners and the perceived inappropriate motivation of 'developers' regarding hazard mitigation and emergency management issues, the authors would welcome any comments from professionals involved in these sectors concerning the issues highlighted in this paper.
} 